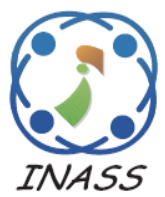

\title{
Optimal Control of Robotic Arm System to Improve Flux Distribution on Dual Parabola Dish Concentrator
}

\author{
Asepta Surya Wardhana ${ }^{1,2 *}$ \\ Mochamad Ashari ${ }^{1}$ \\ Heri Suryoatmojo ${ }^{1}$ \\ ${ }^{1}$ Department of Electrical Engineering, Institut Teknologi Sepuluh Nopember, \\ Surabaya 60111, Indonesia \\ ${ }^{2}$ Department of Instrumentation Engineering, Politeknik Energi dan Mineral Akamigas, \\ Cерu-Blora 58315, Indonesia \\ * Corresponding author's Email: aseptasw@gmail.com
}

\begin{abstract}
To concentrate the rays to the focal point and stabilize the temperature on the receiver were one of the complex works of the two-stage solar concentrator. This paper offers a new method of Fuzzy cascade controller system based on tuning up the optimization at Genetic Algorithm-simple additive weighting (GA-SAW) on the dual parabolic dish concentrator with Compound Parabolic Concentrator. The model and computation of three degrees of freedom robotic arm movement with the ray tracing method were used as the concentrator position predictor. In this research, the acquired fuzzy controller result had an average settling time $0.497 \mathrm{sec}$, and average rise time $0.277 \mathrm{sec}$ faster than a conventional PID controller. This research was able to overcome the disturbance which was diffused rays, so there was a better output with the power and heat flux increased up to $62.49 \%$. The monte carlo ray tracing method from Tonatiuh Software was used to investigate and movement validation of the dual parabola concentrator by showed the flux distribution on the receiver's absorber. In the last stage, an experiment with a prototype had been conducted as a response verification of the controller system which produce a receiver temperature output as high as $121^{\circ} \mathrm{C}$. The final result showed that the controller system managed to optimize the temperature on the receiver's absorber and generate a stable thermoelectric output with power of 1.01 Watt.
\end{abstract}

Keywords: Dual parabola concentrator, Fuzzy cascade controller, Robotic arm, Ray tracing, Genetic algorithm, Thermoelectric.

\section{Introduction}

The development of renewable energy is a big challenge for the world in order to offer a contribution to eco-friendly energy as a replacement for fossil energy. There are several development and innovation on renewable energy technology to obtain an optimal energy conversion system such as clustering photovoltaic [1], wind turbine placement [2], and the development of solar concentrator [3, 4]. The need to have a stable natural resource such as the sun's energy, whereas the earth continues to absorb the solar radiation of $1.7 \times 10^{17} \mathrm{~W}$ [5], so an optimal energy conversion was obtained. The utilization of solar energy to reach a high temperature and efficiency usually with concentrated solar power (CSP) technology [3].

CSP technology for high concentration using two-stage parabola dish concentrators was modelled on some research for instance, the concave shape utilization eliminated the dark areas on the receiver $[6,7], 500 \times$ geometrical concentration improvement [8], the thermal efficiency increased to $68.6 \%$ [9], and have high optical efficiency of $80-82 \%[10,11]$. Several models of two-stage parabolic dish concentrator were only able to be used on small to medium receiver e.g., High Concentrator Photovoltaic (HCPV) and Stirling Engine. In general, the receiver was placed together with the primary concentrator, so if it was used for a bigger scale, it will burden the system. 
Dual Parabolic Dish Concentrator (DPDC) model was able to offer a solution for the receiver system's placement for a bigger scale, which can be placed under the primary concentrator or on the ground [11]. This model used two parabolic dish concentrator and Compound Parabolic Concentrator (CPC) that moved separately. The problem for the DPDC model was there is not any controller system on the 3-DOF (Degree of Freedom) robotic arm as the secondary concentrator actuator, so to concentrate the sun rays to the focal point or receiver on certain time condition and the diffuse ray disturbance was not able applied.

Some control system research and movement optimization for the multi-degree freedom robotic arm with various methods e.g., [12-14] generally was utilized for finding one coordinate point $(x, y, z)$ axis. The optimization searching process of a certain angle on the 3-DOF robotic arm for DPDC was established with a Genetic Algorithm (GA) with the flux distribution output evenly on the receiver absorber [11]. A development on optimization method and solar tracking movement control system was needed to obtain an optimum temperature and robust against the diffuse ray disturbance. There was a good development of solar tracking parabolic and PV that has been done such as dish tracking on ships with an error least than 3.7\% [15], predictive control model for solar furnace [16], two-axis tracking with the gathered energy more than $40 \%$ compared to the fix position [17], 76.42\% more by using active tracking based on astronomical position method [18]. An accurate control system was needed to overcome the real-time sun position angle differences and weather disturbance e.g., diffuse ray.

The motivation for this research is to offer a solution to the development of the controller system on the DPDC model, especially with a 3-DOF robotic arm, so the temperature on the receiver's absorber could be optimized. The main objectives are to predict the position of 3-DOF robotic arm and CPC with the optimization of Genetic AlgorithmSimple Additive Weighting (GA-SAW), the application of fuzzy cascade controller on the secondary concentrator and optimise the flux distribution evenly on the receiver's absorber.

The development of ray tracing computation and interface by the Delphi program. The result of the optimization ray tracing of GA-SAW used as a reference for fuzzy control so it could control the positioning of CPC and the robotic arm's angle. The diffuse ray disturbance improved with positioning optimization of secondary parabola concentrator and CPC with a fuzzy cascade controller method. Monte Carlo Ray Tracing simulation using Tonatiuh
Software were utilised to validate the model and DPDC reflector position. The DPDC prototype was built with their own generator, utilizing thermoelectric to convert heat into electricity, to find the control system performance.

This paper is organized as follows: Section 2 presents our proposed method. Section 3 describes the design of optimization and control. The section 4 describes the results of the investigation and experiment. Finally, in Section 5, we present conclusions and future work.

\section{Proposed method}

\subsection{Dual parabola dish concentrator}

The plan and design making of dual parabola consist of three parts, primary parabola, secondary parabola, and CPC as shown in Fig. 1 [11]. The

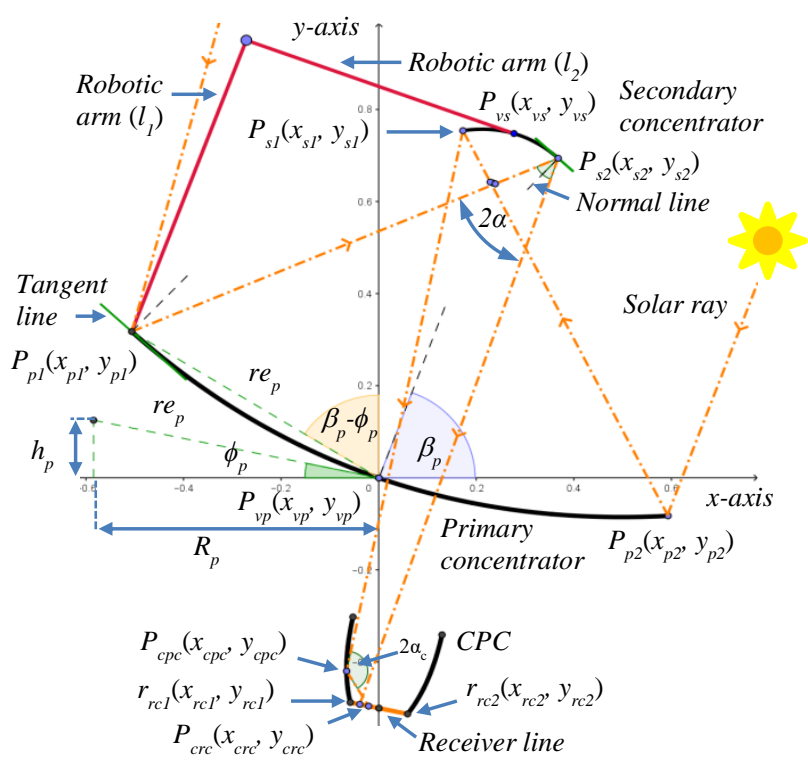

(a)
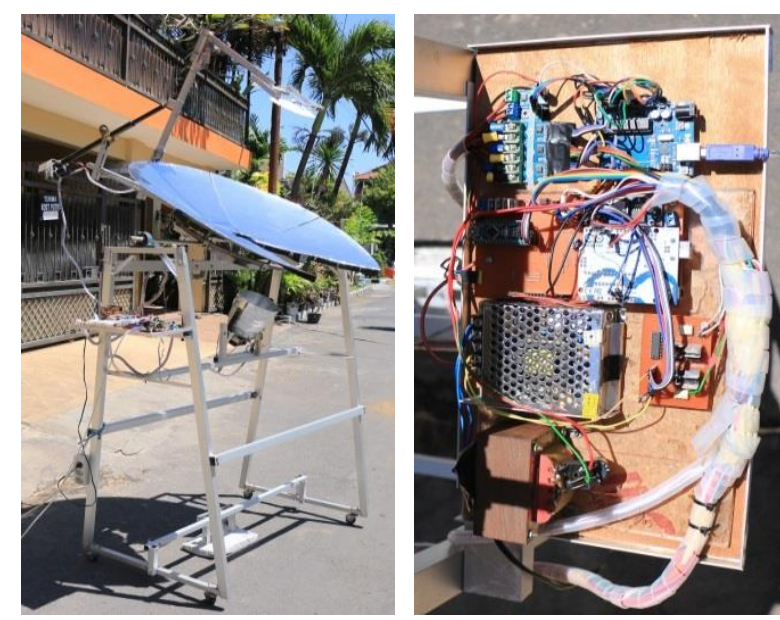

(b)

Figure. 1 The model of dual parabolic dish concentrator:

(a) geometry and (b) prototype 
Table 1. Geometry computational result of DPDC

\begin{tabular}{|l|l|l|}
\hline \multicolumn{1}{|c|}{ Parameter } & Value & Unit \\
\hline Diameter of primary parabola $\left(D_{p}\right)$ & 1.17 & $\mathrm{~m}$ \\
\hline Height of primary parabola $\left(h_{p}\right)$ & 0.125 & $\mathrm{~m}$ \\
\hline Diameter of secondary parabola $\left(D_{s}\right)$ & 0.2042 & $\mathrm{~m}$ \\
\hline Height of secondary parabola $\left(h_{s}\right)$ & 0.0246 & $\mathrm{~m}$ \\
\hline Vertex of secondary parabola $\left(P_{v s}\right)$ & 0.8 & $\mathrm{~m}$ \\
\hline Final focus $\left(f_{e}\right)$ & -0.5 & $\mathrm{~m}$ \\
\hline Acceptance angle $\left(\sigma_{c}\right)$ of CPC & 40 & $\circ$ \\
\hline Height $(\mathrm{H})$ of CPC & 0.1827 & $\mathrm{~m}$ \\
\hline Collector aperture $\left(w_{a}\right)$ of CPC & 0.166 & $\mathrm{~m}$ \\
\hline Width of receiver $w_{r c}$ of CPC & 0.12 & $\mathrm{~m}$ \\
\hline Length of robotic arm $\left(l_{l}\right)$ & 0.675 & $\mathrm{~m}$ \\
\hline Length of robotic arm $\left(l_{2}\right)$ & 0.585 & $\mathrm{~m}$ \\
\hline
\end{tabular}

inputs were diameter, height, and the focus distance of primary parabola and focal length receiver. The mathematical geometry calculation used a basic equation of parabola $y=x^{2} / 4 f_{p}$ with focus parabola on Eq. (1) as in the research by $[6,19]$.

$$
f_{p}=\frac{\left(D_{p} / 2\right)^{2}}{4 h_{p}}
$$

In this research, the receiver's diameter of $0.04 \mathrm{~m}$ was designed following the size of the thermoelectric type of TEC1-12715. There were 4 thermoelectrics in this research. On the receiver, compound parabolic concentrator (CPC) was added to tackle the diffuse ray problem and concentrate the ray so it would be more focused [20].

The design of CPC to the $y$-axis was defined as [21].

$$
y=\frac{x^{2}}{2 w_{r c}\left(1+\sin \sigma_{c}\right)}
$$

The development of DPDC research obtained from the calculation of secondary parabola geometry and compound parabolic concentrator as shown in Table 1 [11]. This geometry design was utilized for the prototype as demonstrated in Fig. 1(b), which their movement system controlled by computer and the microprocessor as the driver.

The design of DPDC used 3-DOF robotic arm to move the concentrator of the secondary parabola that directed the ray to the focal point from the receiver. On the edge of the primary parabola, there was a robotic arm $l_{1}$, connected to $l_{2}$ arm. The position and angle of the joint on every arm calculated with an inverse kinematic method [22]. The first arm moved back and forth, had an angle of
$Q_{1}$ to the $x$-axis. $Q_{1}$ on the arm located on $P_{p l}\left(x_{p l}\right.$, $\left.y_{p l}\right)$, so the equation was [11] :

$$
\begin{aligned}
& Q_{1}= \\
& \operatorname{atan2}\left(\frac{l_{2} \sqrt{1-c_{n}^{2}}\left(x_{v s}-x_{p 1}\right)+\left(l_{1}+\left(l_{2} c_{n}\right)\right)\left(y_{v s}-y_{p 1}\right)}{l_{1}+\left(l_{2} c_{n}\right)\left(x_{v s}-x_{p 1}\right)-\left(l_{2} \sqrt{1-c_{n}^{2}}\left(y_{v s}-y_{p 1}\right)\right)}\right)
\end{aligned}
$$

Where,

$$
c_{n}=\left(\frac{\left(x_{v s}-x_{p 1}\right)^{2}+\left(y_{v s}-y_{p 1}\right)^{2}-l_{1}{ }^{2}-l_{2}{ }^{2}}{2 l_{1} l_{2}}\right)
$$

The alteration of vertex coordinate point of the secondary parabola of $P_{v s}\left(x_{v s}, y_{v s}\right)$ influenced by the deflected ray coordinate point position on the primary parabola $P_{p l}\left(x_{p l}, y_{p l}\right)$. The second arm moved up and down, had an angle of $Q_{2}$ to $l_{l}$ robotic arm:

$$
Q_{2}=\cos ^{-1}\left(\frac{\left(x_{v s}-x_{p 1}\right)^{2}+\left(y_{v s}-y_{p 1}\right)^{2}-l_{1}^{2}-l_{2}^{2}}{2 l_{1} l_{2}}\right)
$$

The deflected ray coordinate points on the surface of the secondary parabola was obtain from $P_{s 1}\left(x_{s 1}, y_{s 1}\right)$ and $P_{s 2}\left(x_{s 2}, y_{s 2}\right)$. The angle of $Q_{3}$ located on joint number 3 , connected to the secondary parabolic concentrator.

$$
Q_{3}=\operatorname{acos}\left(\frac{y_{v s}-\left(y_{s 1}+y_{s 2}\right) / 2}{h_{s}}\right)
$$

\subsection{Ray tracing method}

In this research, the ray tracing method on dual parabolic dish system was developed [11] to find the robotic arm position and CPC on real-time. The principal of Snell Law used to calculate the ray tracing where the incoming angle and reflected angle have the same value [7], [19]. The ray tracing method utilized on the concentrator solar and optic to get the ray distribution on the absorber's surface [5], $[9,10]$. The general line equation of $y=m x+c$ was applied at the ray tracing method. The value of $m_{s}$ was the gradient of the reflected line from the secondary parabola, which has an angle of $2 \alpha_{c}$ to the reflected lines of CPC point $P_{c p c}\left(x_{c p c}, y_{c p c}\right)$. However, the point of $r_{r c 1}\left(x_{r c 1}, y_{r c l}\right)$ and $r_{r c 2}\left(x_{r c 2}, y_{r c 2}\right)$ which was the location of the outermost point from the receiver surface. The final target for the ray tracing was to find $P_{c r c}\left(x_{c r c}, y_{c r c}\right)$ point that the focus point of the absorber's receiver. 


$$
\begin{gathered}
x_{c r c}=\frac{\left(-y_{c p c}-\left(m_{s} x_{c p c}\right)\left(x_{r c 1}-x_{r c 2}\right)\right)}{\left(y_{r c 2}-y_{r c 1}\right)-\left(-\frac{m_{S}+\tan 2 \alpha_{c}}{1-\tan 2 \alpha_{c} m_{s}}\left(x_{r c 1}-x_{r c 2}\right)\right)}- \\
\frac{\left(y_{r c 1}\left(x_{r c 2}-x_{r c 1}\right)-x_{r c 1}\left(y_{r c 2}-y_{r c 1}\right)\right)}{\left(y_{r c 2}-y_{r c 1}\right)-\left(-\frac{m_{S}+\tan 2 \alpha_{c}}{1-\tan 2 \alpha_{c} m_{s}}\left(x_{r c 1}-x_{r c 2}\right)\right)} \\
y_{c r c}=\frac{\left(-\frac{m_{S}+\tan 2 \alpha_{c}}{1-\tan 2 \alpha_{c} m_{s}}\left(x_{r c 1}-x_{r c 2}\right)\right)}{\left(y_{r c 2}-y_{r c 1}\right)-\left(-\frac{m_{S}+\tan 2 \alpha_{c}}{1-\tan 2 \alpha_{c} m_{s}}\left(x_{r c 1}-x_{r c 2}\right)\right)}- \\
\frac{\left(-\left(y_{r c 1}\left(x_{r c 2}-x_{r c 1}\right)-x_{r c 1}\left(y_{r c 2}-y_{r c 1}\right)\right)\right)\left(y_{r c 2}-y_{r c 1}\right)}{\left(y_{r c 2}-y_{r c 1}\right)-\left(-\frac{m_{S}+\tan 2 \alpha_{c}}{1-\tan 2 \alpha_{c} m_{s}}\left(x_{r c 1}-x_{r c 2}\right)\right)}
\end{gathered}
$$

The input which have been given by the ray tracing according to the elevation position of $\left(\beta_{\text {sun }}\right)$ and azimuth $\left(\gamma_{\text {sun }}\right)$ from the sun. Ray tracing conducted by simulation to predict the concentrator's position. Ray tracing computation was done by Delphi Program with flowchart as displayed on Fig. 2.

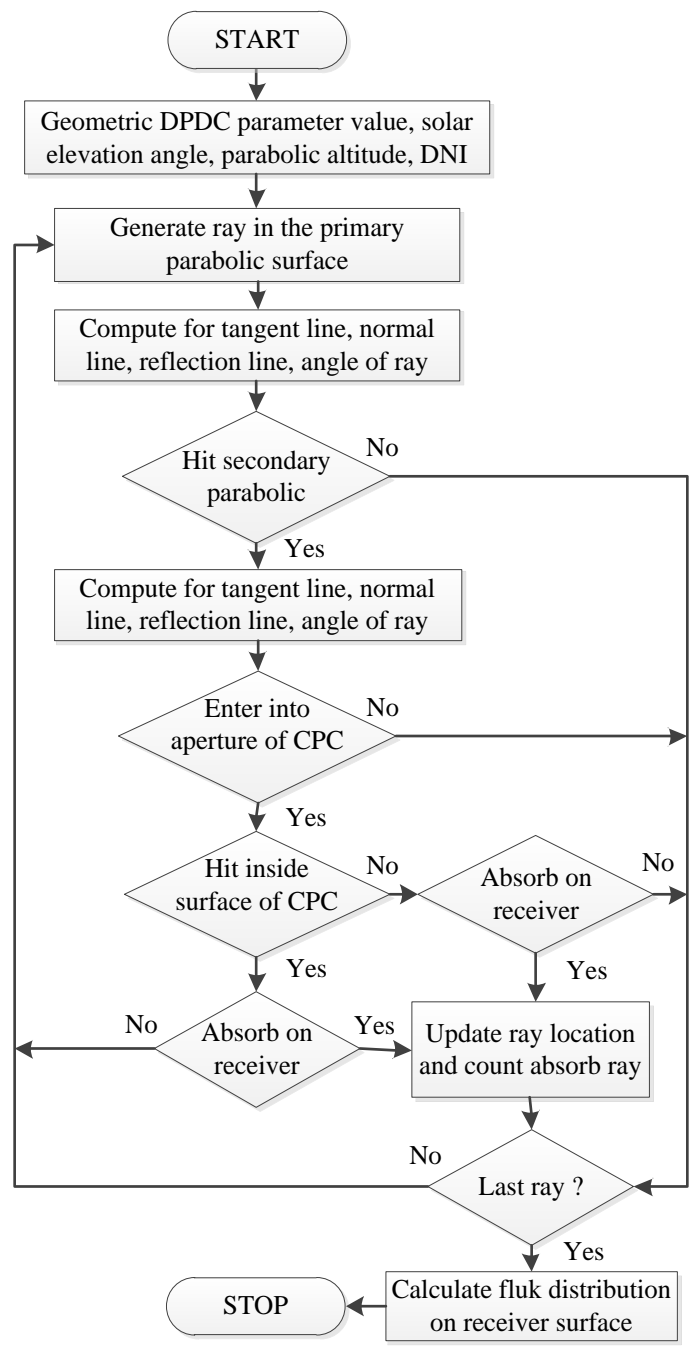

Figure. 2 The flowchart of ray tracing method
Astronomical calculation used to track solar position on real-time was [15] :

The time zone calculation is $h_{t z}=15^{\circ} t z$ and the hour angle calculation:

$$
\begin{aligned}
& \omega=180^{\circ}+h_{t z}-\phi-15^{\circ} h_{t m} \\
& h_{t m}=9.87 \sin (2 B)-7.53 \cos (\mathrm{B})-1.5 \sin (B) \\
& B=\frac{(n-81) 360}{365}
\end{aligned}
$$

The declination angle was:

$$
\delta=23.45^{\circ} \sin \left(\frac{360(280+n)}{365}\right)^{\circ}
$$

So, the value of $\left(\beta_{\text {sun }}\right)$ and $\left(\gamma_{\text {sun }}\right)$ :

$$
\begin{aligned}
& \beta_{\text {sun }}=\sin ^{-1}(\cos \delta \cos \phi \cos \omega+\sin \phi \sin \delta) \\
& \gamma_{\text {sun }}=\cos ^{-1}\left(\frac{\sin \delta \cos \phi-\cos \delta \sin \phi \cos \omega}{\cos \beta_{\text {sun }}}\right)
\end{aligned}
$$

Where,

$$
\begin{aligned}
& t z \text { is time angle, } \\
& h_{t m} \text { is equation of time, } \\
& \phi \text { is latitude of the location, } \\
& n \text { is number of day. }
\end{aligned}
$$

\subsection{The control method}

The control system for dual parabolic dish concentrator operated two parts of the concentrator which were the primary concentrator and secondary concentrator including the CPC as shown in Fig. 3. The target of the primary concentrator was the sun position of $\beta_{\text {sun }}$ and $\gamma_{\text {sun }}$ from the astronomic calculations. The output result from the primary concentrator position was the value of $\beta_{p}$ and $\gamma_{p}$ which could be used as an input for angle calculation on the robotic arms of $Q_{1}, Q_{2}, Q_{3}$ and CPC rotation angle $\left(\sigma_{r}\right)$. This angle calculation was done by GA-SAW computation to obtain an optimal temperature on the absorber receiver. The control system which was used drives the primary concentrator, $Q_{1}$ and $Q_{2}$ robotic arms utilized the Fuzzy Logic Controller (FLC) single close loop with gyro sensor as the feedback control.

An advanced controller needed to operate several conditions which affected each other in one process. Fuzzy cascade controller could improve this condition because it had primary and secondary control loop. The applications of fuzzy cascade controller have been administered in several times $[23,24]$. 


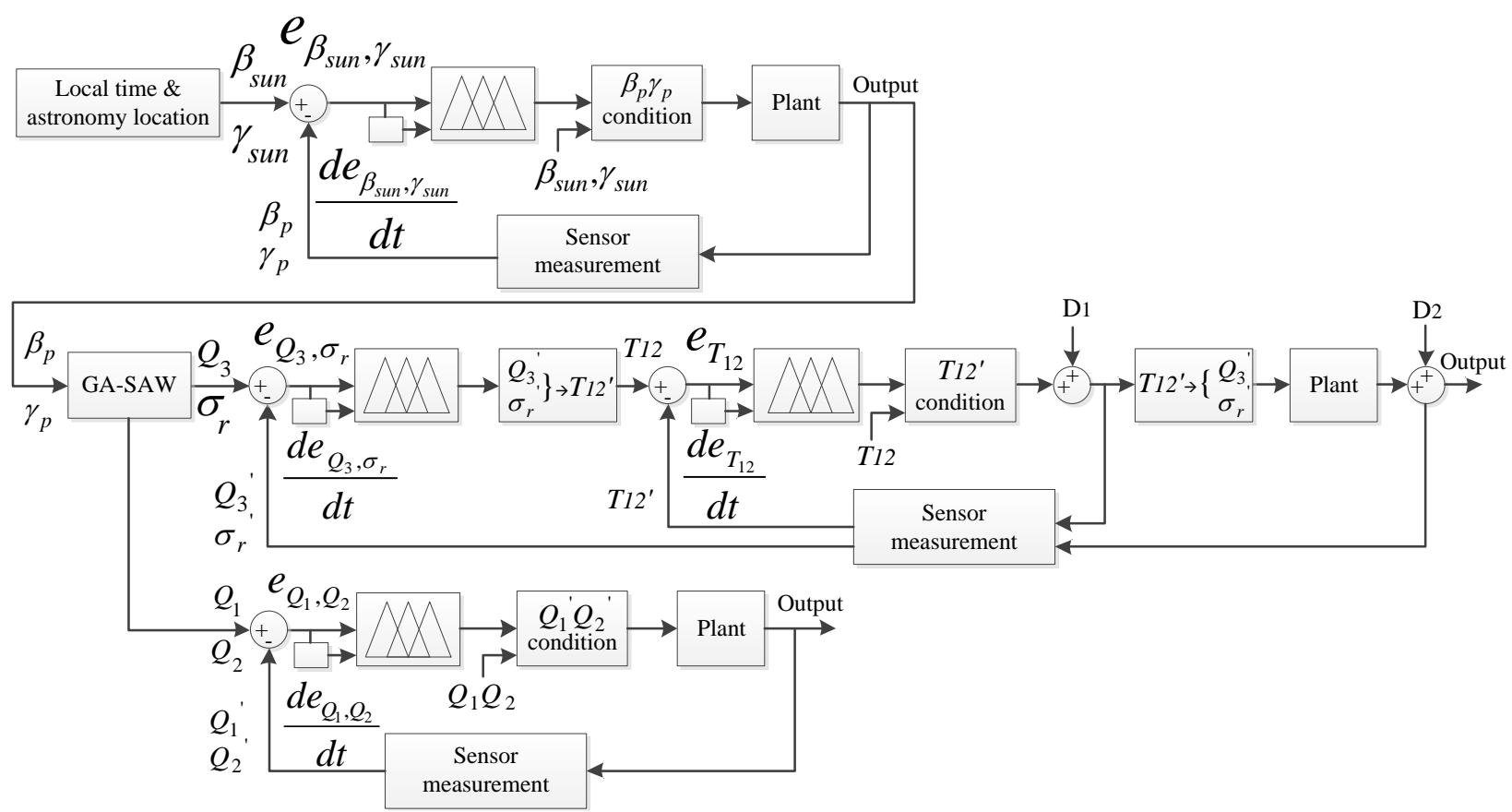

Figure. 3 The control system of dual parabolic dish concentrator

The secondary controller designed to react when an disturbance occurred, so it would maintain the output properly. The primary controller's role was to give the output as a reference value on the second loop. In this case, the value of $Q_{3}$ and $\sigma_{r}$ responded based on the GA-SAW's result in a condition that the output result reached stability. Moreover, to maintain the optimal temperature condition on the absorber receiver, the $Q_{3}$ and $\sigma_{r}$ used the fuzzy cascade with gyro sensor feedback and thermocouple sensor. This fuzzy cascade utilization was useful to respond towards the $D_{1}$ and $D_{2}$ disturbance i.e. diffuse ray.

\section{The optimization and control design}

\subsection{Robotic arm movement}

The mathematical calculation process of robotic arm movement was done with Eq. (3) to (6), but in order to obtain the arm position with an optimal angle, considering the amount of ray concentrator to the receiver was hard to calculate it conventionally, hence why an optimization computation on the robotic arm was needed. Some research about robotic arm optimization with end effector at one point were achieved with Genetic Algorithm (GA) program on 2-DOF [13], 6-DOF [14], [25]. This research also employed the Genetic Algorithm method to finish the ray tracing optimization with a population size parameter of 80 , the crossover of 0.6 and the mutation rate of 0.01 . In the early stage of this research, a sampling process had been done to find the sun elevation angle, started from $30^{\circ}$ until $90^{\circ}$ as a primary data, which later it will be used as an input in a real-time process. The GA optimization process conducted with the mathematical equation with a ray tracing method where Eq. (12) as an objective function to find the focus point of the receiver [11].

$$
F_{o b j}=\sum_{i=1}^{n} \sqrt{\left(x_{c r c 1, i}-x_{G A 1, i}\right)^{2}+\left(x_{c r c 2, i}-x_{G A 2, i}\right)^{2}}
$$

Fig. 4 displayed a movement pattern graphic of the robotic arms 1 and 2 and the end effector point at the $x-y$ axis. From the optimization result, it is shown that the robotic arm position has a linear motion, following the pattern of solar rays movement.

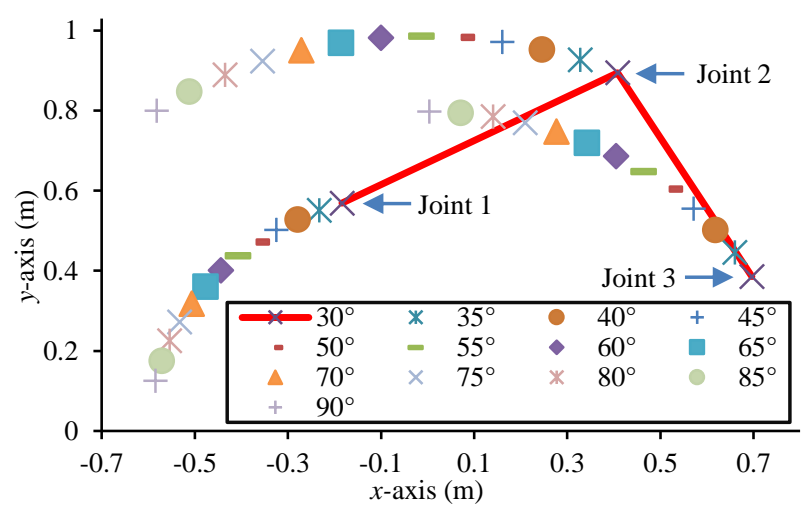

Figure. 4 The robotic arm movement for sun elevation $30^{\circ}-90^{\circ}$ 
This pattern facilitated the angle searching process of the robotic arm for different sun position. Linearly, the transformation angles on the robotic arm were obtained, with values of $Q_{1}, Q_{2}, Q_{3}$ and CPC rotation angle $\left(\sigma_{r}\right)$ as shown in Fig. 5. The angle value of $Q_{l}$ tended to follow the pattern from sun elevation because the joint 1 attached on the edge of the primary parabola. The outcome of this optimization process was the initial prediction answer from the position and angle of the secondary parabola concentrator.

To speed up the position searching process of the secondary parabola, the initial outcome was converted into a linear regression equation. The goal was it could be used in real-time utilizing the sun position calculation on local time.

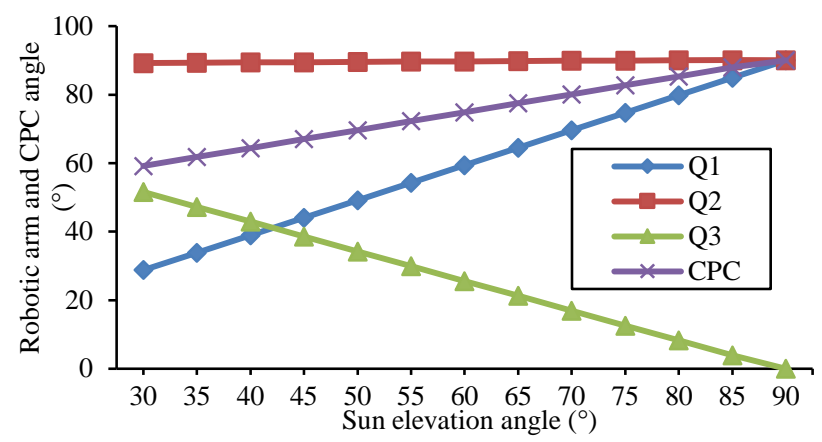

Figure. 5 The rotation angle of $Q_{1}, Q_{2}, Q_{3}$ and CPC $\left(\sigma_{r}\right)$

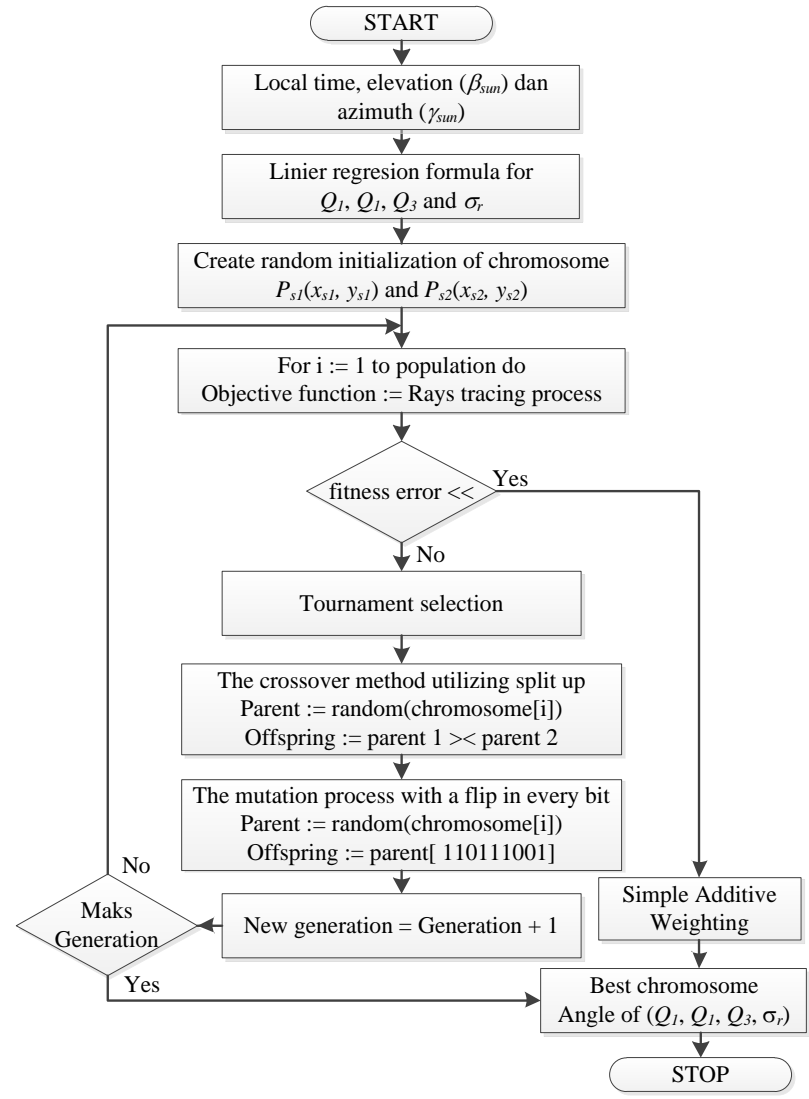

Figure. 6 The flowchart GA-SAW
The linear regression was acquired from an equation such as:

$$
\begin{aligned}
& Q_{1}=-1.8093+1.0203 \beta_{\text {sun }} \\
& Q_{2}=88.7402+0.0158 \beta_{\text {sun }} \\
& Q_{3}=77.5945-0.8665 \beta_{\text {sun }} \\
& \sigma_{r}=43.49-0.5233 \beta_{\text {sun }}
\end{aligned}
$$

The linear regression output used as an approach against the outcome target. In order to reach optimal temperature condition on the heat receiver, so reoptimization was done with genetic algorithm with the addition of simple additive weighting as revealed in Fig. 6.

\subsection{Simple additive weighting}

A control process needed a fast and accurate response time when making a decision to get an optimal result. As revealed in Fig. 6, the optimization process from the genetic algorithm still in global optimum reach, where there were several results needed to be selected based on the target condition. To produce a local optimum, the ray result needed to be reviewed several output criteria. The final result selection was conducted by a Simple Additive Weighting (SAW) scale system with various criteria:

$C_{1}=$ the total of the incoming ray at the target,

$C_{2}=$ the number of heat flux on the center of the receiver,

$C_{3}=$ the total of heat flux,

$C_{4}=$ the heat flux deviation

$C_{5}=$ the deviation of the incoming ray on the receiver.

Simple additive weighting used to find the accumulative weight score from rating performance in every alternative on every attribute [26, 27].

The equation for maximum criteria:

$$
r_{i j}=\frac{x_{i j}}{\operatorname{Max}_{i} x_{i j}}
$$

The calculation for minimum criteria:

$$
r_{i j}=\frac{\operatorname{Min}_{i} x_{i j}}{x_{i j}}
$$

The simple additive weighting method was evaluating every alternative result with an equation:

$$
V_{i j}=\sum_{j=1}^{n} w_{j} r_{i j}
$$


Table 2. The weighting criteria of heat flux optimization

\begin{tabular}{|c|c|c|c|c|}
\hline \multicolumn{3}{|c|}{ Maximum } & \multicolumn{2}{c|}{ Minimum } \\
\hline C1 & C2 & C3 & C4 & C5 \\
\hline 0.4 & 0.34 & 0.06 & 0.19 & 0.01 \\
\hline
\end{tabular}

Where:

$r_{i j}=$ The value of normalized performance

$x_{i j}=$ The attribute value which every criterion

$V_{j}=$ The rank of every alternative

$w_{j}=$ The weight value of every criterion

$\operatorname{Max}_{i} x_{i j}=$ The biggest value of every criterion

$\operatorname{Min}_{i} x_{i j}=$ The smallest value of every criterion

In this research, a hybrid of Genetic Algorithm and Simple Additive Weight was implemented as an optimization system of flux distribution. The weighting criterion divided into a maximum and a minimum as demonstrated on Table 2.

\subsection{Fuzzy controller}

Fuzzy logic had been applied in several applications because their easy and reliable control system i.e., DC geared motors driver [15], stepper motor [22]. This research used fuzzy control to control the primary concentrator and the robotic arms position, so the concentration direction was accurate and produced an optimum temperature. The input from the fuzzy system was angle value of $Q_{l}$, $Q_{2}, Q_{3}$ and $\sigma_{r}$ from the GA-SAW optimization result. The system employed the closed-loop controller as plant feedback, utilized the figure from temperature sensor measurement and gyro sensor. The control inputs were an error $(e)$ and error of change $(d e)$. The output from the fuzzy logic controller was a command signal, which later, it commanded the DC plant motor. The error and error of change for elevation $\left(\beta_{\text {sun }}\right)$, and azimuth $\left(\gamma_{\text {sun }}\right)$ on the primary concentrator used the Eq. (22) as revealed below :

$$
\begin{gathered}
\left\{\begin{array}{c}
e_{\beta_{\text {sun }}, \gamma_{\text {sun }}}(t)=\left\{\begin{array}{c}
\left(\beta_{\text {sun }}-\beta_{p}\right) \rightarrow 0^{\circ} \leq\left(\beta_{\text {sun }}, \beta_{p}\right) \leq 90^{\circ} \\
\left(\gamma_{\text {sun }}-\gamma_{p}\right) \rightarrow 0^{\circ} \leq\left(\gamma_{\text {sun }}, \gamma_{p}\right) \leq 360^{\circ}
\end{array}\right. \\
\operatorname{de}_{\beta_{\text {sun },}, \gamma_{\text {sun }}}(t)=e_{\beta_{\text {sun }}, \gamma_{\text {sun }}}(t)-e_{\beta_{\text {sun }}, \gamma_{\text {sun }}}(t-1)
\end{array}\right.
\end{gathered}
$$

On the secondary concentrator, there were two robotic arms with error and error of change for $Q_{1}$ and $Q_{2}$, used Eq. (23) as shown below:

$$
\left\{\begin{array}{c}
e_{Q_{1}, Q_{2}}(t)=\left\{\begin{array}{l}
\left(Q_{1}-Q_{1}{ }^{\prime}\right) \rightarrow 0^{\circ} \leq\left(Q_{1}, Q_{1}{ }^{\prime}\right) \leq 90^{\circ} \\
\left(Q_{2}-Q_{2}{ }^{\prime}\right) \rightarrow 0^{\circ} \leq\left(Q_{2}, Q_{2}{ }^{\prime}\right) \leq 90^{\circ}
\end{array}\right. \\
d e_{Q_{1}, Q_{2}}(t)=e_{Q_{1}, Q_{2}}(t)-e_{Q_{1}, Q_{2}}(t-1)
\end{array}\right.
$$

The setpoint value from the angle compared with the number from temperature condition to achieve small error number, which leads to an optimum temperature. The secondary concentrator motor on the end effector and CPC rotation angle $\left(\sigma_{r}\right)$ used the error and error of change formula on Eq. (24), which cascade with temperature control on Eq. (25), as followed:

$$
\begin{gathered}
\left\{\begin{array}{c}
e_{Q_{3}, \sigma_{r}}(t)=\left\{\begin{array}{c}
\left(Q_{3}-Q_{3}{ }^{\prime}\right) \rightarrow 0^{\circ} \leq\left(Q_{3}, Q_{3}{ }^{\prime}\right) \leq 90^{\circ} \\
\left(\sigma_{r}-\sigma_{r}{ }^{\prime}\right) \rightarrow 0^{\circ} \leq\left(\sigma_{r}, \sigma_{r}^{\prime}\right) \leq 90^{\circ}
\end{array}\right. \\
d e_{Q_{3}, \sigma_{r}}(t)=e_{Q_{3}, \sigma_{r}}(t)-e_{Q_{3}, \sigma_{r}}(t-1)
\end{array}\right. \\
\left\{\begin{array}{c}
e_{T_{12}}(t)=\left(T_{12}-T_{12}{ }^{\prime}\right) \rightarrow 0^{\circ} \mathrm{C} \leq\left(T_{12}, T_{12}{ }^{\prime}\right) \leq 150^{\circ} \mathrm{C} \\
d e_{T_{12}}(t)=e_{T_{12}}(t)-e_{T_{12}}(t-1)
\end{array}\right.
\end{gathered}
$$

Membership function had a vital role in increasing the fuzzy control performance. On every variable input from $e$ and $d e$ of the FLC, used to operate the DC motor control, which had 5 membership function $(m f)$. The membership function tuning on the fuzzy controller with genetic algorithm managed to reduce error on tracking motion 2-DOF robot [28], so in this system, the membership functions numbers obtained from GASAW optimization result. Fuzzy sets were defined as Negative Big (NB), Negative Small (NS), Zero (ZE), Positive Small (PS) and Positive Big (PB), as displayed on Fig. 7:

On this fuzzy control, the triangle membership function was utilized to compare three transformation condition of the temperature value, which have an acute value variations. The advantage were it was able to detect a small temperature modification and suggested an accurate and quick decision for the control process of the motor velocity. The output of the fuzzy result was PWM number which controls the movement speed of the DC Motor. DC motor was able to move clockwise $(\mathrm{CW})$, or counter-clockwise $(\mathrm{CCW})$, as demonstrated on Fig. 8:

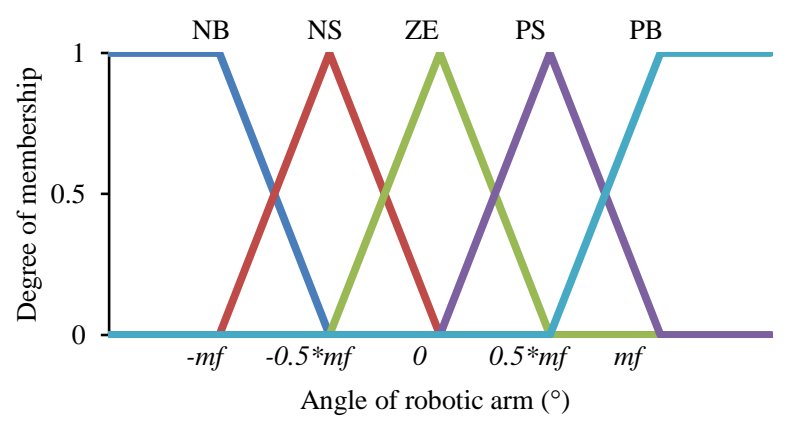

Figure. 7 The membership function of fuzzy $(e)$ and $(d e)$ 


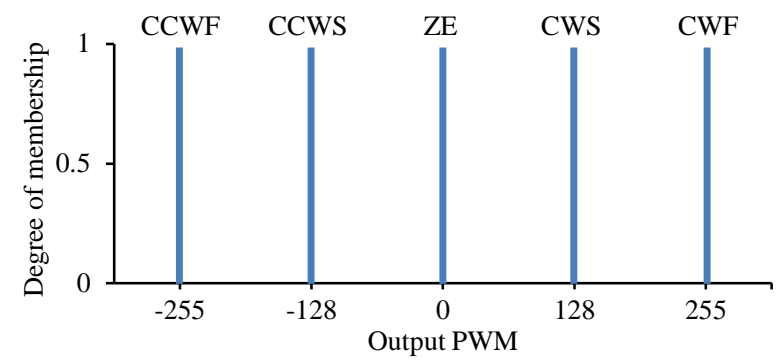

Figure. 8 The fuzzy output

Table 3. The function rules of fuzzy $(e)$ and $(d e)$

\begin{tabular}{|c|c|c|c|c|c|}
\hline $\boldsymbol{d e}$ & $\mathbf{N B}$ & $\mathbf{N S}$ & $\mathbf{Z E}$ & $\mathbf{P S}$ & $\mathbf{P B}$ \\
\hline $\mathbf{N B}$ & CCWF & CCWF & CCWS & CCWS & ZE \\
\hline NS & CCWF & CCWS & CCWS & ZE & CWS \\
\hline ZE & CCWS & CCWS & ZE & CWS & CWS \\
\hline PS & CCWS & ZE & CWS & CWS & CWF \\
\hline PB & ZE & CWS & CWS & CWF & CWF \\
\hline
\end{tabular}

The Mamdani Rule applied on Fuzzy Inference System (FIS) in form of IF-THEN statement, this was an easy rule and have been used on computation a lot. The defuzzification process transformed the fuzzy output to crip output, using the Centre of Gravity Method (COG) [12]. The modification of angular position from the secondary parabola and the temperature difference from the sensor processed with 25 control rules of Fuzzy Mamdani. The rule was displayed in the Table 3, which was used in the fuzzy controller of dual parabola concentrator.

\section{Result and discussion}

\subsection{The scenario and investigation for concentrator movement}

A small change at the elevation position $\left(\beta_{\text {sun }}\right)$ and the azimuth $\left(\gamma_{\text {sun }}\right)$ from the sun causing the focus point shifted on the receiver, which led to less optimum heat flux on the receiver. One way to optimize it was controlling the parabolic concentrator's position so the sun rays could concentrate right to the receiver. Table 4 revealed a comparison between two transformations of movement condition scenarios from the concentrator in order to investigate the heat flux value on the receiver's surface.

On the first scenario, every joint moved so it needed an accurate control and time to obtain the right position. On the second scenario, half of the joints moved, and the other half stopped, in order to find the efficiency from the motion control. From the scenario in Table 4 , the system condition of the
Table 4. The scenario rule for concentrator movement

\begin{tabular}{|l|c|c|}
\hline \multirow{2}{*}{ Condition } & Scenario $($ Sc) \\
\cline { 2 - 3 } & First & Second \\
\hline \multicolumn{2}{|c|}{ Primary parabola concentrator } \\
\hline Joint azimuth $\left(\gamma_{\text {sun }}\right)$ & Move & Move \\
\hline Joint elevation $\left(\beta_{\text {sun }}\right)$ & Move & Fix \\
\hline Secondary parabola concentrator \\
\hline Joint $1\left(Q_{1}\right)$ & Move & Fix \\
\hline Joint $2\left(Q_{2}\right)$ & Move & Fix \\
\hline Joint $3\left(Q_{3}\right)$ & Move & Move \\
\hline Compound parabolic concentrator \\
\hline Joint CPC $\left(\sigma_{r}\right)$ & Move & Move \\
\hline
\end{tabular}

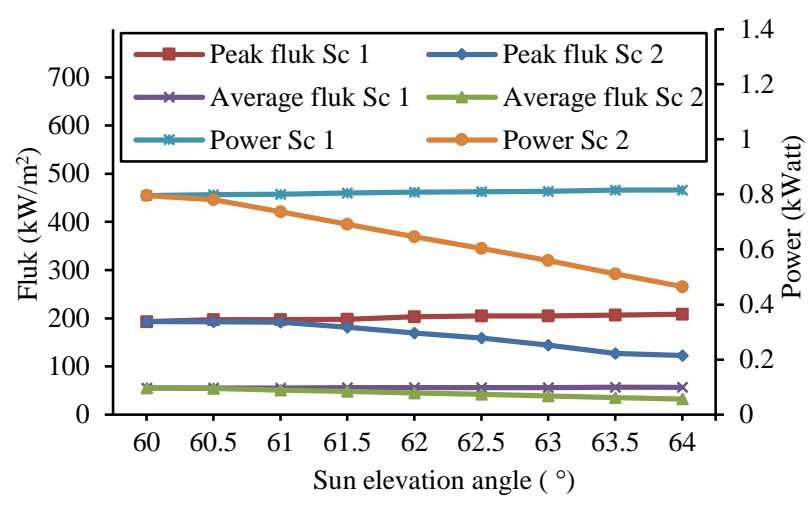

Figure. 9 The peak, average flux, and power for the sun elevation angle $60^{\circ}-64^{\circ}$ investigations

every $0.5^{\circ}$ interval or \pm 2 minutes against the sun position.

The calculation for sun position use Eq. (10) and Eq. (11), then the GA-SAW computation was done to get optimization angle of $Q_{1}, Q_{2}, Q_{3}$ and CPC rotation angle $\left(\sigma_{r}\right)$. This investigation used an example of the sun elevation angle $\left(\beta_{\text {sun }}\right)$ at $60^{\circ}-64^{\circ}$. Fig. 9 displayed the findings of the heat flux and power difference result between two scenarios.

Fig. 9 showed that scenario number 1 had bigger heat flux and power on every sun elevation angle change. It was caused by every joint position adapted to the GA-SAW optimization result. Whereas for scenario number 2, there was not any heat flux decreasing to the $\beta_{\text {sun }}$ transformation at $0.5^{\circ}$ to $1^{\circ}$. Moreover, on $\beta_{\text {sun }}>1^{\circ}$, there was a significant number of differences caused by the heat flux declined. In general, the result from the second scenario was the peak flux and average flux reduced by $36.39 \%$ and $41.52 \%$ respectively. The first scenario result revealed that the sun elevation increased linearly with peak flux and average flux inclined of $7.31 \%$ and $2.48 \%$ respectively. The power in the first scenario rose by $2.48 \%$, and in the second scenario fell $41.52 \%$. 


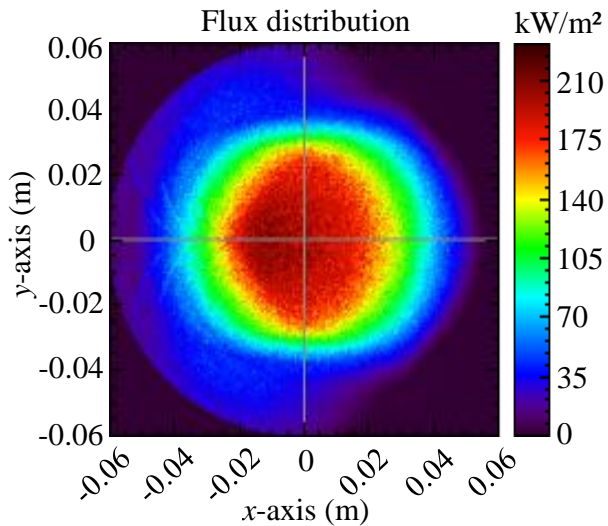

(a)

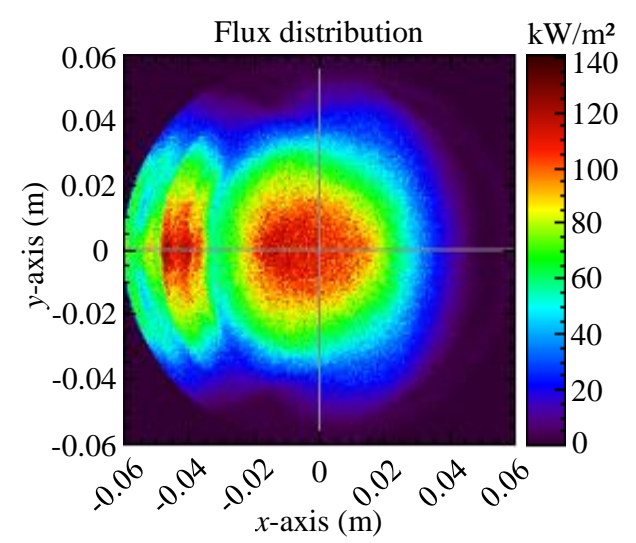

(b)

Figure. 10 The distribution of flux from the sun elevation angle investigation of $64^{\circ}$ on: (a) first scenario and (b) second scenario

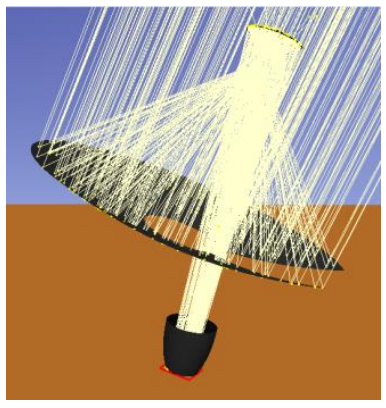

(a)

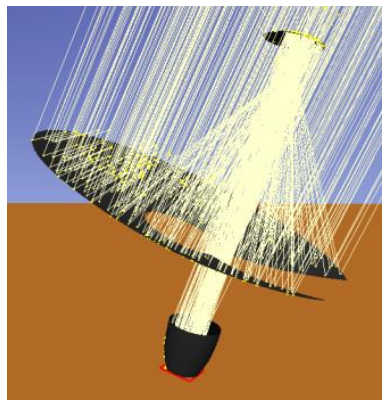

(b)
Figure. 11 The ray tracing simulation from the sun elevation investigation with an angle of $64^{\circ}$ on:

(a) first scenario and (b) second scenario

From the investigation result of two scenarios, the first scenario model for main movement control application was the one that could be used, whereas the second scenario was used as a positioning improvement control if there was an error or diffused ray in less than two minutes. Thus, the fuzzy cascade control on $Q_{3}$ and $\sigma_{r}$ were utilized to optimize the temperature on the receiver's surface. The GA-SAW investigations result validated with Monte Carlo Ray Tracing (MCRT) method on
Tonatiuh Software to find the heat flux value and the flux distribution value.

Fig. 10(a) demonstrated that the flux distribution from the first scenario had a concentrated peak flux on the coordinate $(-0.003,-0.003)$ of $231 \mathrm{~kW} / \mathrm{m}^{2}$ and the average flux was $56 \mathrm{~kW} / \mathrm{m}^{2}$. In contrast with scenario number 2 where there were two spots of peak flux on the left side of the receiver. This happened because the limited position of the secondary concentrator made it quite hard to concentrate the rays to the receiver and ended up with several rays scattered and caught by the CPC. On the second scenario, the peak flux decreased 140 $\mathrm{kW} / \mathrm{m}^{2}$ and the average flux fell $32 \mathrm{~kW} / \mathrm{m}^{2}$. The amount of power produced with scenario number one was 815 Watt, whereas with scenario number two was 464 Watt, so overall there were $42.94 \%$ differences between the first and second scenario.

Fig. 11(a) displayed an illustration of ray tracing on the first scenario, which illustrated the ray direction towards the focal point on the condition where every ray concentrated on the middle of the receiver. Fig. 11(b) illustrated the ray tracing result on the second scenario, where the ray from the primary concentrator was only able to be aught by secondary concentrator half of it, so the result tended to scatter and there were several ray losses. The theoretical calculation which GA-SAW computed the optimization success to validate it with ray tracing simulation of Tonatiuh Software.

\subsection{The response comparison of fuzzy cascade and PID controller}

This study displayed a comparison between fuzzy cascade response of the control system and PID conventional controller, with several interferences such as the incoming sun rays and temperature difference. The testing result used a sun elevation angle $\beta_{\text {sun }}$ of $60^{\circ}$ where the joint angle value $Q_{1}=59.411^{\circ}, Q_{2}=89.709^{\circ}, Q_{3}=25.55^{\circ}$ and $\sigma_{r}=76.12^{\circ}$. Fig. 12 showed the response time of the joint angle on $Q_{1}$ and $Q_{3}$ with the fuzzy controller.

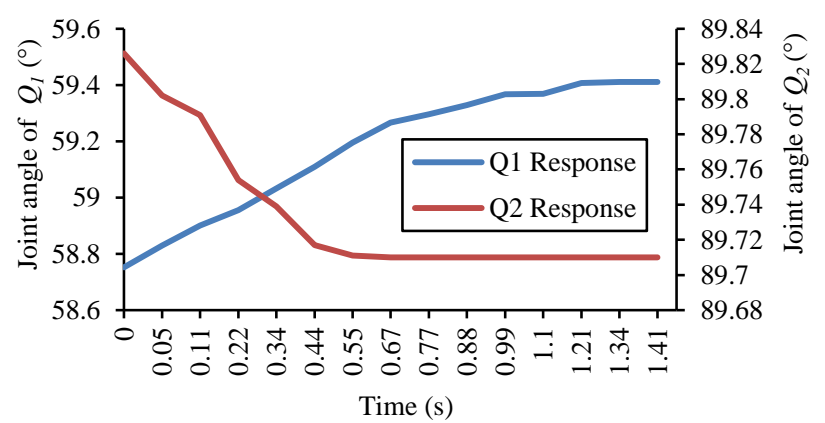

Figure. 12 The response time of $Q_{1}$ and $Q_{2}$ using the fuzzy controller on sun elevation of $60^{\circ}$ 
It revealed that on sun elevation $\beta_{\text {sun }}=59^{\circ}$, they only needed $0.55 \mathrm{sec}$ to reach the $Q_{2}$ 's target from the previous condition. The next stage was comparing the response time of fuzzy controller and PID, thus the performance of joint number $3\left(Q_{3}\right)$ of the secondary controller against the transformation or disturbance of sun ray direction could be found.

The utilization of PID control in general, have been applied to several driver motor application [15], [18]. The PID setting control have been through a trial and error with $K_{P}=2.6, K_{l}=0.005$ and $K_{D}=0.04$ with an equation below:

$$
u(t)=K_{P} e(t)+K_{I} \int e(t) d t+K_{D} \frac{d e(t)}{d t}
$$

Fig. 13 demonstrated the contrast between $Q_{3}$ positioning control response when the incoming sun rays got interfered on $-0.2^{\circ}, 0.3^{\circ},-0.5^{\circ}, 1^{\circ}$ and $0.5^{\circ}$. When the disturbance appeared at $-0.2^{\circ}$, the $Q_{3}$ angle responded with an angle improvement on $26.209^{\circ}$ with $\sigma_{r}=75.79^{\circ}$, within $1.872 \mathrm{sec}$. At extreme interference such as $1^{\circ}$ deviation needed $2.762 \mathrm{sec}$ to reach a stable condition. It caused by the angle from an earlier position with $Q_{3}$ target angle of $22.573^{\circ}$ and $\sigma_{r}=75.3^{\circ}$ had a farther distance. As long as the disturbance happened between $-1^{\circ} \geq$ error $\leq 1^{\circ}$, so the $\sigma_{r}$ had a transformation range from $-1^{\circ}$ till $1^{\circ}$ from normal angle condition.

The response time output distinction between fuzzy and PID controller could be seen in Table 5. The fuzzy controller had an average settling time $\left(T_{s}\right) 0.497 \mathrm{sec}$, and average rise time $\left(T_{r}\right) 0.277 \mathrm{sec}$ faster than a conventional PID controller. This comparison result showed the fuzzy cascade control had a better response than PID conventional controller.

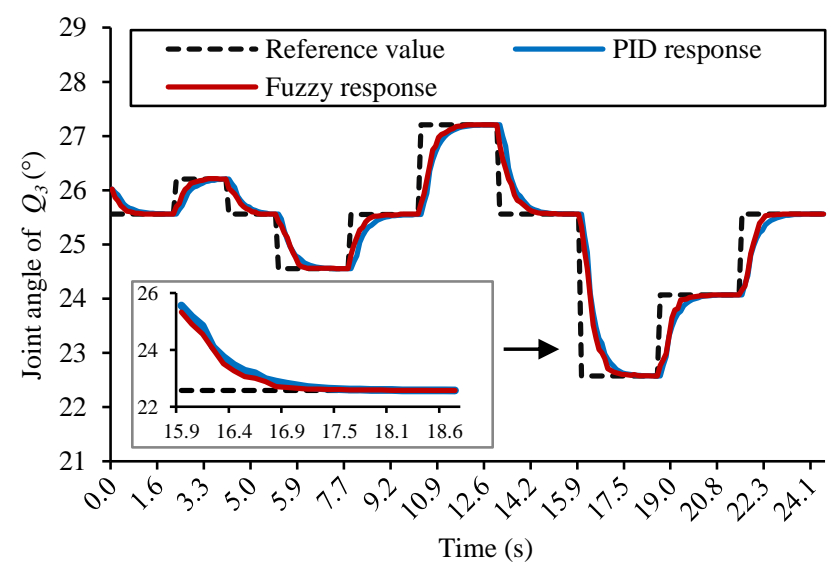

Figure. 13 The comparison response of $\mathrm{Q}_{3}$ using fuzzy cascade and PID controller on sun elevation of $60^{\circ}$
Table 5. The comparison between the response output for fuzzy and PID controller

\begin{tabular}{|c|c|c|c|c|c|c|}
\hline \multirow{2}{*}{ نี } & \multicolumn{3}{|c|}{ Fuzzy } & \multicolumn{3}{|c|}{ PID } \\
\hline & $\begin{array}{c}T_{r} \\
(\mathbf{s e c})\end{array}$ & $\begin{array}{c}T_{s} \\
(\mathbf{s e c})\end{array}$ & $\begin{array}{c}\text { Error } \\
\text { position } \\
(\%)\end{array}$ & $\begin{array}{c}T_{r} \\
(\mathbf{s e c})\end{array}$ & $\begin{array}{c}T_{s} \\
(\mathrm{sec})\end{array}$ & $\begin{array}{c}\text { Error } \\
\text { position } \\
(\%)\end{array}$ \\
\hline 0 & 0.55 & 1.1 & 0.00195 & 0.9 & 1.64 & 0.003205 \\
\hline$-0.2^{\circ}$ & 0.67 & 0.99 & 0.01144 & 0.99 & 1.64 & 0.018840 \\
\hline $0.3^{\circ}$ & 0.66 & 1.12 & 0.00407 & 1 & 2.08 & 0.003125 \\
\hline$-0.5^{\circ}$ & 0.78 & 1.33 & 0.00036 & 1.02 & 1.55 & $1.93 \mathrm{E}-05$ \\
\hline $1^{\circ}$ & 0.78 & 1.23 & $4.2 \mathrm{E}-05$ & 0.89 & 1.62 & $4.20 \mathrm{E}-05$ \\
\hline $0.5^{\circ}$ & 0.67 & 1.32 & $1.98 \mathrm{E}-05$ & 0.99 & 1.53 & $1.97 \mathrm{E}-05$ \\
\hline
\end{tabular}

The fuzzy cascade control considered two conditions, which were the target angle position and heat flux as feedback. In contrast with similar research, the fuzzy controller had better advantages, it could adapt to the nonlinear system, so it could follow the changes faster [29, 30].

Fig. 14 exhibited a heat flux result from the raytracing simulation with the input of sun irradiation of $I_{s}=1000 \mathrm{~W} / \mathrm{m}^{2}$ and material reflectivity of $95 \%$. From this model, a heat flux data from ray-tracing computation was acquired, which later clustered into several pieces, thus the number of photons scattered on the receiver's surface could be discovered.

As displayed on Fig. 14, at disturbance $1^{\circ}$ happened in $15.906 \mathrm{sec}$ to $16.277 \mathrm{sec}$, where sensor $2\left(S_{t m p 2}\right)$ was zero, because, in this condition, the rays tended to go out from the receiver area. When sensor $1\left(S_{t m p 1}\right)$ and sensor $2\left(S_{t m p 2}\right)$ have same heat flux value so the error value was smaller or almost zero, which indicated that the distribution of flux had spread evenly and had reached the optimal condition.

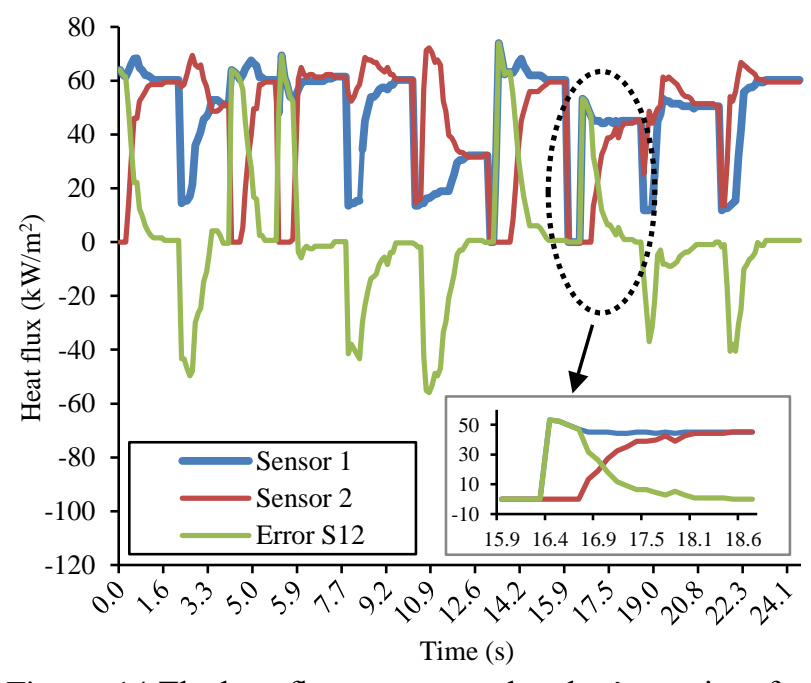

Figure. 14 The heat flux output on absorber's receiver for fuzzy cascade controller 


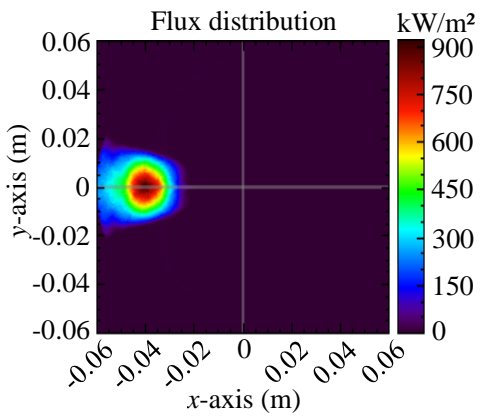

(a)

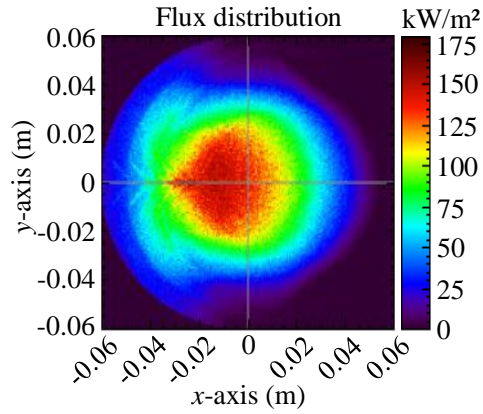

(b)

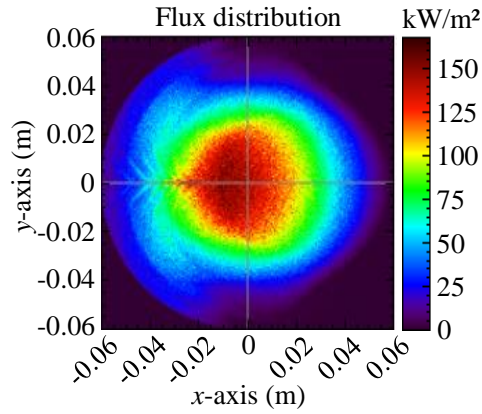

(c)

Figure. 15 The flux distribution when $1^{\circ}$ interference occurred to the response of: (a) $T M_{1}$, (b) $T M_{2}$, and (c) $T M_{3}$

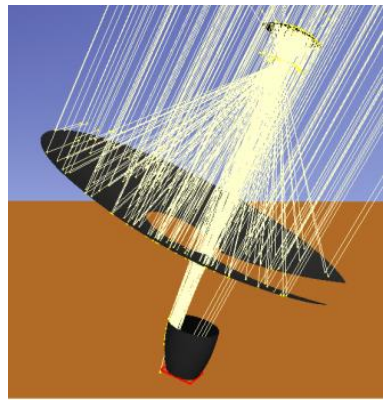

(a)

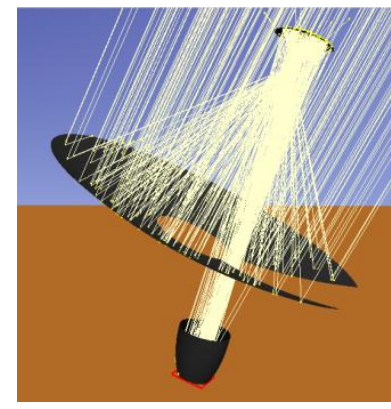

(b)

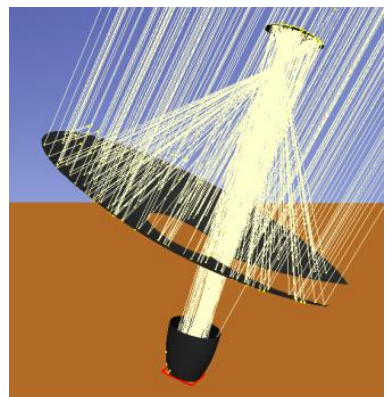

(c)

Figure. 16 The ray-tracing simulation of fuzzy response at $1^{\circ}$ on the response of (a) $T M_{1}$ (b) $T M_{2}$ (c) $T M_{3}$

We validated the heat flux computational result from controller respond with MCRT simulation on Tonatiuh Software to find the flux distribution on the absorber's receiver. Fig. 15 displayed the simulation result with the distribution of flux on the condition of $T M_{l}=15.906 \mathrm{sec}, T M_{2}=16.928 \mathrm{sec}$ and $T M_{3}=18.56 \mathrm{sec}$. On $T M_{1}$ condition, the average number of heat flux and power were $24 \mathrm{~kW} / \mathrm{m}^{2}$ and 351.766 Watt, respectively. The flux distribution occurred at the edge of the receiver, and the concentration point became smaller spot. These led to unevenly heat produced and not an optimal performance from the receiver.

The simulation results on $T M_{2}$ and $T M_{3}$ have almost similar output value with the average heat flux of $39 \mathrm{~kW} / \mathrm{m}^{2}$ where it produced power of 572.091 Watt and 571.597 Watt. Although both had almost similar output, $T M_{3}$ condition had more equal flux distribution. The peak distribution of heat flux located in the middle with the coordinate of $(-0.0063$, 0.0069) with the average heat flux and power increased $62.49 \%$. The secondary concentrator's position in this system was very crucial to determine the direction of the reflected ray to the focal point. As Fig. 16 illustrated the simulation of ray tracing direction transformation, caused by the $1^{\circ}$ interference of the sun.

On the initial condition, there was not any change from the secondary concentrator position. Therefore, on the $T M_{l}$ condition, the secondary concentrator still located on $Q_{3}=25.32^{\circ}$ causing the direction of ray did not concentrate to the centre of the receiver. When we compared with $T M_{2}$ and $T M_{3}$ positions, we were able to see that the ray direction had been concentrated to the center of the receiver. Fuzzy cascade controller of the secondary concentrator repeatedly improved the position until an equal flux distribution obtained, and in the end, the secondary concentrator position was received with $Q_{3}=22.57^{\circ}$ and the time response was 2.762 sec.

The simulation experimentation above was done according to the ideal condition which was the primary concentrator position in accordance to the azimuth and elevation and the arm angles of $l_{1}$ and $l_{2}$, which was consistent to the calculation. On the second experiment, it was done non-ideal condition, for example the positioning error on arm angle $l_{1}$ or $l_{2}$, which could happen on real plant condition. In this investigation, the initial angle of arm $l_{l}$ was $Q_{l}=59.411^{\circ}$, and later, when an error occurred turned to $Q_{l}=59.61^{\circ}$. No change occurred for $Q_{2}=89.709^{\circ}, Q_{3}=25.55^{\circ}$ and $\sigma_{r}=76.12^{\circ}$. The aim was to see the response of control system while adjusting the secondary parabola position, in order to reach an even heat distribution on the receiver surface. Fig. 17 displayed the comparison of fuzzy cascade control and PID, which was observed from the flux distribution result on the receiver surface. 


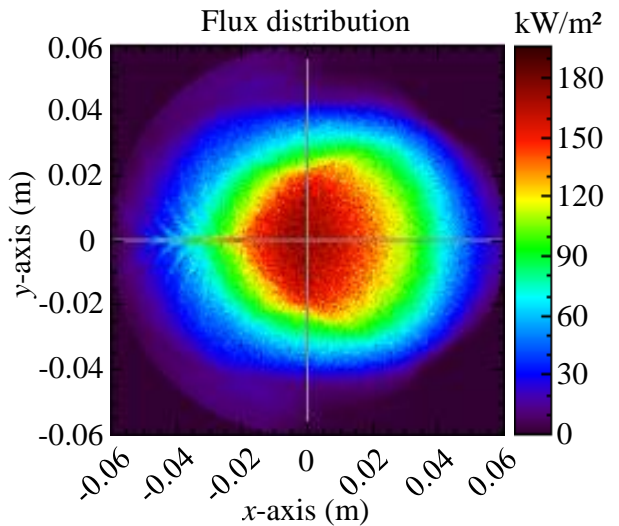

(a)

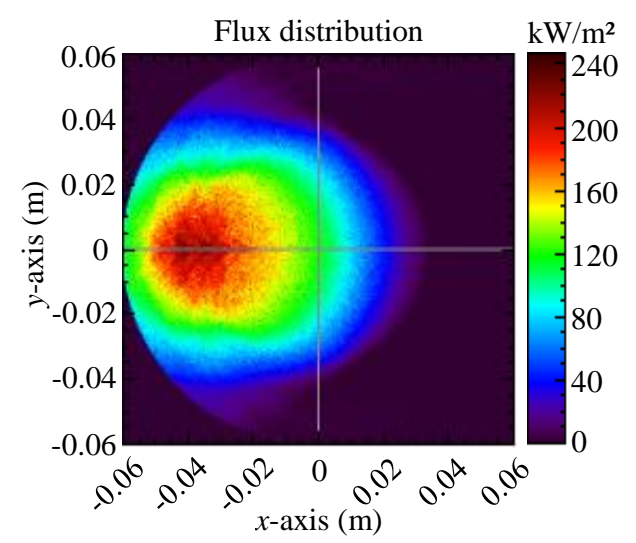

(b)

Figure. 17 The flux distribution when angle $l_{l}$ error occurred: (a) Fuzzy cascade and (b) PID

The GA-SAW optimization fixed the initial position of vertex $P_{v s}\left(x_{v s}, y_{v s}\right)$ secondary parabola $P_{v s}(0.4047,0.6872)$ into $P_{v s}(0.4037,0.6902)$. On the fuzzy cascade control system, the GA-SAW input reference value was utilized as the initial inquiry, and later it was analyzed on the second stage to acquire a stable temperature condition. In this experiment, the fuzzy cascade control system was very effective adjusting the heat distribution evenly, with modified the angle of $Q_{3}=24.85^{\circ}$. Therefore, it was difference with PID control which based only on unfocused concentration result and uneven flux distribution.

\subsection{The prototype experiment}

This subchapter explored the controller respond on $Q_{3}$ joint and the temperature optimization on the receiver using the prototype. The prototype as illustrated in Fig. 1(b) had been used to verify the obtained result of the previous method and simulation. The application of the control system in this experiment utilizing the closed-loop controller methods. Therefore, the controller feedback as the data signal was needed for the input using gyro sensor MPU6050 and thermocouple of K-Type with
MAX6675 driver. Three thermocouple sensors placed on the left side $\left(S_{t m p l}\right)$ and on the right side $\left(S_{t m p 2}\right)$ with the distance from the centre $0.04 \mathrm{~m}$, and the last sensor $\left(S_{t m p 3}\right)$ located on the middle of the receiver, in order to observe the temperature's change. On the receiver's surface, four types of thermoelectric TEC-12715 were placed as a conversion output of heat to power. Thermoelectric was one of the potential Nano power electric generator [31]. The electric power generated by the thermoelectric, which attained from energy balance [32]:

$$
P_{t e c}=Q_{h}-Q_{c}
$$

This experiment conducted on 21-22 October 2019 , at 09.13 , with the sun azimuth $\gamma_{s u n}=99.7^{\circ}$, and sun elevation $\beta_{\text {sun }}=60^{\circ}$. Two pairs of photodiode sensors detected the incoming sun rays and act as a ray intensity comparison to the primary concentrator. The experimentation demonstrated the controllable and stable temperature condition on the receiver and created an optimal power. Illustration Fig. 18 and 19 displayed the two days temperature measurement result on the receiver's surface

The first-day experiment showed there was external interference at 171 seconds until 238 seconds, leading to unstable temperature. At $274 \mathrm{sec}$, the controlled managed to fix the secondary controller position, thus the heat concentration stayed at the middle of the receiver.

Fig. 19 showed the second-day investigation's result, which revealed the condition was relatively

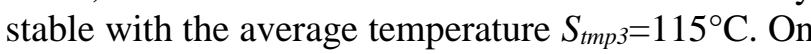
the first-day investigation, the average temperature $S_{\text {tmp } 3}=121^{\circ} \mathrm{C}$ which higher than the second-day outcome, however, the unstable condition on $S_{t m p l}$ and $S_{\text {tmp } 2}$ caused unevenly heat distribution on the receiver.

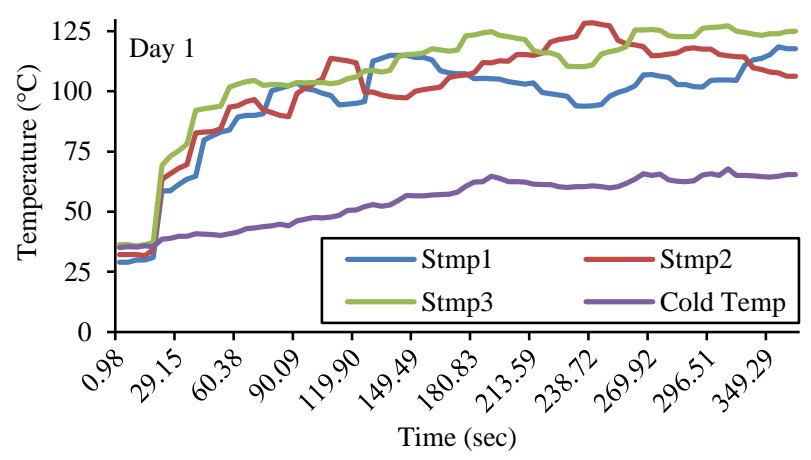

Figure. 18 The temperature measurement experiment result on the receiver day 1 


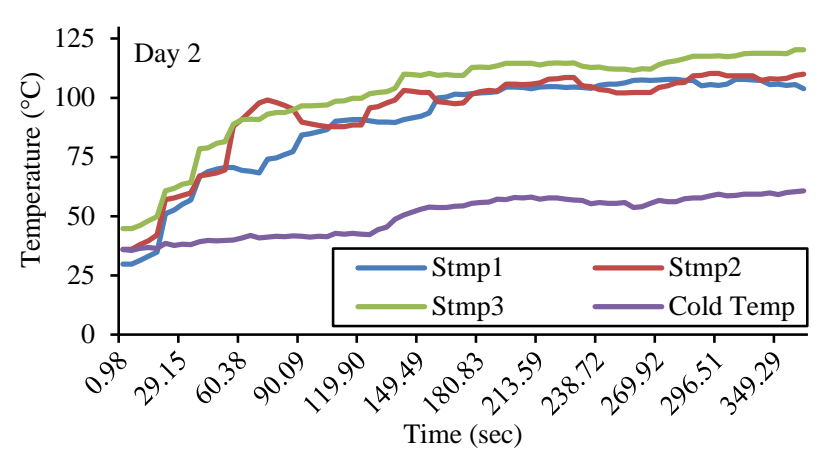

Figure. 19 The temperature measurement experiment result on the receiver day 2

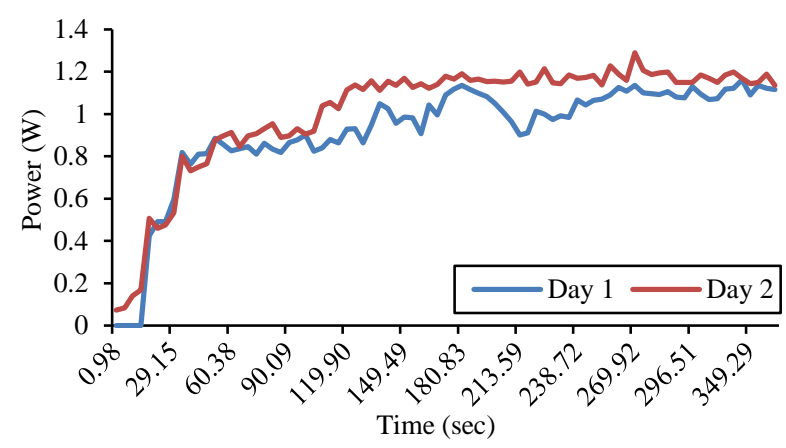

Figure. 20 The thermoelectric measurement output experiment result

A single parabola, with a diameter of 3.56 meter could produce a temperature of $109.85^{\circ} \mathrm{C}$ [33]. The utilization of dual parabolic dish concentrator was more efficient with a smaller diameter so it could get temperature $10.15 \%$ higher.

From both, first-day and second-day experiments, the produced current and electric voltage from the thermoelectric were obtained, as illustrated in Fig. 20. The focus of this research was to keep the optimal power when external disturbance appeared. The interruption on the first day made the power decreased from 1.15 Watt to 0.9 Watt, at 213 seconds. At 265 secs, the control stabilized with power of 1.15 Watt. On the second day, the control stabilized starting from 124 secs, and the power was 1.13 Watt, so the average power produced on the second day, which was 1.01 Watt, higher than the first day's power, 0.91 Watt.

The investigation on the conventional thermoelectric application without water cooler produced the temperature differences on the hot and cold side of $65^{\circ} \mathrm{C}$, with a generated voltage of 0.55 Volt [34], and produced power less than 1 Watt [32]. In this study, the maximum produced voltage was 2.3 Volt, with a temperature difference of $59^{\circ} \mathrm{C}$. The higher the temperature difference on both sides of the thermoelectric, the bigger the power produced.

\section{Conclusions and future work}

The optimization method and 3-DOF robotic arm controller system successfully implemented on Dual Parabolic Dish Concentrator model with CPC. The GA-SAW optimization method could predict and optimize the movement position of the robotic arm on several sun direction changes condition. The single fuzzy controller on the primary concentrator and fuzzy cascade on the second concentrator managed to overcome the sun direction interference at an angle of $1^{\circ}$, which increased the power of $62.49 \%$. The result of the fuzzy controller had a better response with settling time $\left(T_{s}\right) 0.497 \mathrm{sec}$ and average rise time $\left(T_{r}\right) 0.277$ secs, compared to conventional PID. The experiment used the application of fuzzy cascade controller system at DPDC prototype generated optimum temperature and power on the receiver. The utilization of DPDC with smaller diameter could raise the temperature on absorber's receiver up to $10.15 \%$, compared to single dish concentrator. For future work on this experiment, we were able to develop a robotic arm design to be more efficient to increase the performance of the controller system.

\section{Acknowledgments}

The authors would like to express their gratitude to the Indonesian Ministry of Energy and Mineral Resources for their financial support for this doctoral research and to the developer of Tonatiuh software facilitating the flux distribution analysis.

\section{References}

[1] A. Rajagukguk, C. W. Priananda, D. C. Riawan, and M. Ashari, "Prototype of Power Optimization Based on Converter Topologies Reconfiguration Using PV String Smart Clustering Method for Static Miniature Photovoltaic Farm Under Partially Shaded Condition", International Review of Automatic Control, Vol. 10, No. 4, pp. 289-295, 2017.

[2] D. Hendrawati, A. Soeprijanto, and M. Ashari, "Turbine Wind Placement with Staggered Layout as a Strategy to Maximize Annual Energy Production in Onshore Wind Farms", International Journal of Energy Economics and Policy, Vol. 9, No. 2, pp. 334-340, 2019.

[3] D. Barlev, R. Vidu, and P. Stroeve, "Innovation in concentrated solar power", Solar Energy Material \& Solar Cells, Vol. 95, No. 10, pp. 2703-2725, 2011.

[4] J. Coventry and C. Andraka, "Dish systems for CSP”, Solar Energy, Vol. 152, pp. 140-170, 
2017.

[5] Q. Mao, Y. Shuai, and Y. Yuan, "Study on radiation flux of the receiver with a parabolic solar concentrator system", Energy Conversion and Management, Vol. 84, pp. 1-6, 2014.

[6] Y. T. Chen and T. H. Ho, "Design method of non-imaging secondary (NIS) for CPV usage", Solar Energy, Vol. 93, pp. 32-42, 2013.

[7] Q. Cheng, J. Chai, Z. Zhou, J. Song, and Y. Su, "Tailored non-imaging secondary reflectors designed for solar concentration systems", Solar Energy, Vol. 110, pp. 160-167, 2014.

[8] K. Shanks, N. Sarmah, J. P. Ferrer-rodriguez, S. Senthilarasu, K. S. Reddy, and E. F. Ferna, "Theoretical investigation considering manufacturing errors of a high concentrating photovoltaic of cassegrain design and its experimental validation", Solar Energy, Vol. 131, pp. 235-245, 2016.

[9] S. Yang, J. Wang, P. D. Lund, C. Jiang, and B. Huang, "Design and performance evaluation of a high-temperature cavity receiver for a 2-stage dish concentrator", Solar Energy, Vol. 174, pp. 1126-1132, 2018.

[10] F. Dähler, M. Wild, R. Schäppi, P. Haueter, and T. Cooper, "Optical design and experimental characterization of a solar concentrating dish system for fuel production via thermochemical redox cycles", Solar Energy, Vol. 170, pp. 568-575, 2018.

[11] A. S. Wardhana, M. Ashari, and $H$. Suryoatmojo, "Designing and modeling a novel dual parabolic concentrator with three degree of freedom (DOF) robotic arm", Solar Energy, Vol. 194, pp. 436-449, 2019.

[12] D. D. Ligutan, L. J. S. Cruz, M. C. D. P. Del Rosario, J. N. S. Kudhal, A. C. Abad, and E. P. Dadios, "Design and Implementation of a Fuzzy Logic-based Joint Controller on a 6-DOF Robot Arm with Machine Vision Feedback", In: Proc. of International Conf. on Computing Conference, pp. 249-257, 2017.

[13] S. Refoufi and K. Benmahammed, "Control of a manipulator robot by neuro-fuzzy subsets form approach control optimized by the genetic algorithms", ISA Transactions., Vol. 77, pp. 133-145, 2018.

[14] P. P. R. Filho, S. P. da Silva, V. N. Praxedes, J. Hemanth, and V. H. C. de A. Jude Hemanth, "Control of singularity trajectory tracking for robotic manipulator by genetic algorithms", Journal of Computational Science, Vol. 30, pp. 55-64, 2019.

[15] B. Setiawan, M. H. Purnomo, and M. Ashari, "A High Precision Angle Compensation
Controller For Dish Solar Tracker installed on a Moving Large Ship", International Review of Automatic Control, Vol. 6, No. 6, pp. 695-700, 2013.

[16] B. A. Costa, J. M. Lemos, and E. Guillot, "Control of a Solar Furnace using MPC with Integral Action", IFAC-PapersOnLine, Vol. 49, No. 7, pp. 961-966, 2016.

[17] W. Nsengiyumva, S. G. Chen, L. Hu, and X. Chen, "Recent advancements and challenges in Solar Tracking Systems (STS): A review", Renewable and Sustainable Energy Reviews, Vol. 81, pp. 250-279, 2018.

[18] A. Z. Hafez, A. M. Yousef, and N. M. Harag, "Solar tracking systems: Technologies and trackers drive types - A review", Renewable and Sustainable Energy Reviews, Vol. 91, pp. 754-782, 2018.

[19] A. S. Wardhana, H. Suryoatmojo, and M. Ashari, "Optimization of heat flux distribution on dual parabolic dish for Stirling engine applications", In: Proc. of the International Conference on Sustainable Energy Engineering and Application, pp. 6-11, 2017.

[20]A. H. Jaaz, H. A. Hasan, K. Sopian, M. H. B. H. Ruslan, and S. H. Zaidi, "Design and development of compound parabolic concentrating for photovoltaic solar collector: Review", Renewable and Sustainable Energy Reviews, Vol. 76, pp. 1108-1121, 2017.

[21] M. G. Sheth and P. K. Shah, "Design and development of compound parabolic concentrating solar collector with flat plate absorber", International Journal of Innovative Research in Science, Engineering and Technology, Vol. 2, No. 8, pp. 3884-3889, 2013.

[22] A. El-sherbiny, M. A. Elhosseini, and A. Y. Haikal, "A comparative study of soft computing methods to solve inverse kinematics problem", Ain Shams Engineering Journal, Vol. 9, No. 4, pp. 2535-2548, 2018.

[23] S. Oh, W. Kim, and W. Pedrycz, "Design of optimized cascade fuzzy controller based on differential evolution: Simulation studies and practical insights", Engineering Applications of Artificial Intelligence, Vol. 25, No. 3, pp. 520532, 2012.

[24] P. Mahalakshmi and S. Poornapushpakala, "Simulation of Cascade Control for a Multiprocess Station using Fuzzy Logic", In: Proc. of International Conf. on Communications and Signal Processing, pp. 1768-1772, 2015.

[25] B. Nadir and O. Mohammed, "Optimization the 
Trajectories of Robot Manipulators Along Specified Task", International Journal of Intelligent Engineering and Systems, Vol. 11, No. 1, pp. 11-19, 2018.

[26] A. Afshari, M. Mojahed, and R. M. Yusuff, "Simple Additive Weighting approach to Personnel Selection problem", International Journal of Innovation, Management and Technology, Vol. 1, No. 5, pp. 511-515, 2010.

[27] I. Irvanizam, "Multiple Attribute Decision Making with Simple Additive Weighting Approach for Selecting the Scholarship Recipients at Syiah Kuala University", In: Proc. of International Conf. on Electrical Engineering and Informatics, pp. 245-250, 2017.

[28] A. O. Pizarro-Lerma, R. García-Hernández and V. A. Santibáñez, "Fine-Tuning of a Fuzzy Computed-Torque Control for a 2-DOF Robot via Genetic Algorithms", IFAC-PapersOnLine, Vol. 51, No. 13, pp. 326-331, 2018.

[29] N. J. S. Amlashi, "Design and Implementation of Fuzzy Position Control System for Tracking Applications and Performance Comparison with Conventional PID”, International Journal of Artificial Intelligence, Vol. 1, No. 1, pp. 3144, 2012.

[30] H. E. Abdel-maksoud, M. M. Khater, and S. M. Shaaban, "Adaptive Fuzzy Logic PI Control for Switched Reluctance Motor Based on Inductance Model", International Journal of Intelligent Engineering and Systems, Vol. 10, No. 4, pp. 41-49, 2017.

[31] M. Y. Fauzan, S. Islam, S. M. Muyeen, A. S. Wardhana, and M. Ashari, "Experimental Modeling of Nano Power Generation using Thermoelectric Generator (TEG) from Incinerator Waste Heat", In: Proc. of the Seminar on Intelligent Technology and Its Applications, pp. 67-70, 2018.

[32] C. A. Mgbemene, J. Duffy, H. Sun, and S. O. Onyegegbu, "Electricity generation from a compound parabolic concentrator coupled to a thermoelectric module", Journal of Solar Energy Engineering, Vol. 132, No. 3, 2008.

[33] G. Muthu, S. Shanmugam, and A. R. Veerappan, "Solar parabolic dish thermoelectric generator with acrylic cover", In: Proc. of the 4th International Conference on Advances in Energy Research, Vol. 54, pp. 210, 2014.

[34] R. Hájovský, M. Pieš, and L. Richtár, "Analysis of the Appropriateness of the Use of Peltier Cells as Energy Sources", Sensors, Vol. 16, No. 6, pp. 1-13, 2016. 